\title{
ANALYSIS OF SEASONAL VARIATIONS IN COORDINATES FOR SOME IGS STATIONS
}

\author{
Khaled Mahmoud Abdel Aziz \\ Department of Surveying Engineering, Shoubra Faculty of Engineering, Benha University, \\ Cairo, Egypt. \\ Corresponding Author's E-mail: Khaled.Mahmoud@feng.bu.edu.eg
}

Received: 21 March 2021 Accepted: 30 May 2021

\begin{abstract}
The accuracy obtained by processing the GPS observations is important in several applications. This research, using the three different techniques for processing GNSS/CORS stations to illustrate the variation in coordinates of some GNSS/CORS stations on each month at two different years using the GPS observations.

In this research, we obtained the GPS observations of five stations for one day in every month over 24 months. We tried to have the same day of each month, but there were some problems in the observation of these stations, which led to the replacement of the day in some months. The differences of coordinates between every two successive months in 2018 and 2019 at all IGS stations when using the SECTOR tool at SOPAC technique are within $5 \mathrm{~mm}$. But when using TBC and CSRS-PPP techniques we detected that the differences in coordinates between every two successive months for IGS stations in 2018 are not the same as in 2019. By fixing the coordinates obtained by the SOPAC technique and compared to other techniques, in TBC the common months between two years, which gives a high difference for all IGS stations coordinates are July, August, October, November, March and December. But when using CSRS-PPP, the difference in IGS coordinates in 2018 differs from 2019 for all months.
\end{abstract}

\section{KEYWORDS:}

Trimble Business Center (TBC), Vector Length (VL), Position Error (PE), International Terrestrial Reference Frame (ITRF), and International GNSS Service (IGS).

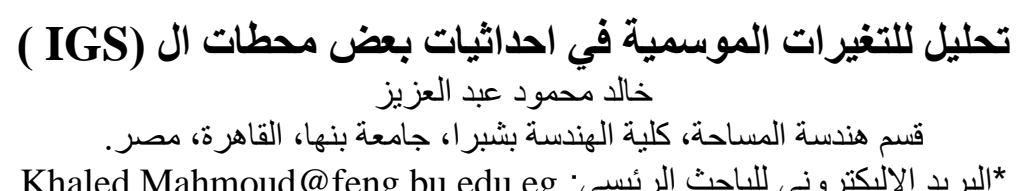




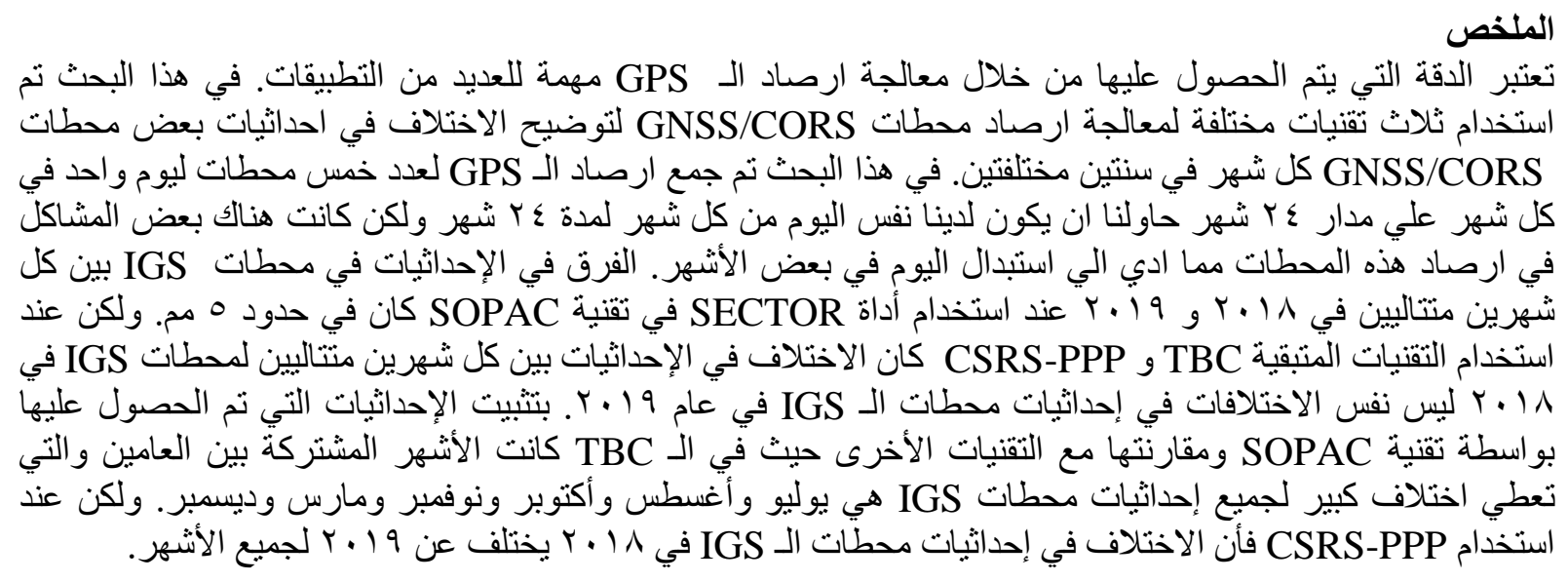

\section{INTRODUCTION}

There are number of errors both systematic and random, including ephemeris errors, satellite and receiver clock errors, propagation errors and random observation errors which effect on GPS measurements. The GPS signals are affected by the ionosphere and troposphere errors (Webster,I.,1993). The ionosphere is approximately located between 50 to $1000 \mathrm{~km}$ above the earth surface. The location error is associated with the ionosphere which is directly proportional to the Total Electron Content (TEC) contained along the signal trajectory in the ionospheric and it is inversely proportional to the square of signal frequency. The effect of the troposphere depends on the atmosphere density and elevation angle of the satellite. The effect of the tropospheric observed from the terrestrial surface up to about $50 \mathrm{~km}$. The representation of the troposphere deviation depends on the atmospheric temperature, atmospheric pressure, and water vapour pressure (Celestino,C etal., 2012).

(Cole, D etal.,2009) taking Australian GPS continuous observation stations data to extract TEC. It is analysed the ionospheric TEC daily variations in 2006, and hourly variations in a sample day in Winter, Autumn, Summer and Spring. Using the data from 14 Australia GPS continuous observation stations to determined TEC spatial distribution during 2006. The result shows the TEC values in Summer and Spring are higher, and have more obvious variability, than during Autumn and Winter.

(Akhoondzadeh, M etal., 2018) Illustrate the monthly mean variation of TEC over IRAN, the results showed that the TEC values are maximum in the spring seasons (April) and in winter seasons (December) the TEC values are minimized. The TEC values are increased from winter to spring and TEC values are decreased from spring to summer and summer to autumn.

\section{STUDY AREA AND DATA SOURCES}

In this research, five IGS stations (BSHM, DRAG, RAMO, NICO and MERS) were used see figure (1). Three techniques of processing (TBC- CSRS-PPP and SECTOR tool at SOPAC) were used to determine the positions of these stations at one day in each month in 2018 and the same days on the same months in 2019. The time of observation is 24 hours. 


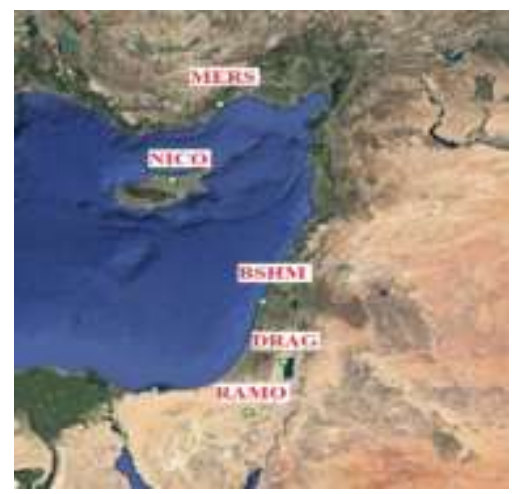

Figure 1: The five IGS stations locations (http://www.igs.org/network).

- The RINEX observation data files of five IGS stations were obtained from (http://sopac-old.ucsd.edu/dataBrowser.shtml).

- The RINEX observations were processed by TBC using the precise ephemeris which were obtained from (ftp://cddis.nasa.gov/gnss/products/).

- In TBC technique, BSHM station was used as fixed station. The coordinates of BSHM station were obtained from (http://sopac-old.ucsd.edu/sector.shtml).

\section{PROCESSING TECHNIQUES}

\subsection{TRIMBLE BUSINESS CENTER (TBC)}

The Trimble Business Center (TBC) has replaced Trimble Geomatics Office (TGO) as Trimble's GPS data processing software. The TBC software suite is a desktop application for processing and managing optical, GNSS, and imaging survey data (Unavco,2021).

\subsection{SCRIPPS EPOCH COORDINATE TOOL AND ONLINE RESOURCE (SECTOR)} Using the SOPAC site to obtain the fixed coordinates of CORS stations used in this research by SECTOR tool. The SECTOR is a utility to compute coordinates at any epoch of time for over 2000 global and regional continuous GPS stations analysed by SIO and JPL and archived at SOPAC. The coordinates $(\mathrm{X}, \mathrm{Y}, \mathrm{Z})$ are defined with respect to a geocentric Earth-fixed reference frame in ITRF 2008. The SECTOR also gives the coordinates in a geodetic system. The epoch-date coordinates are based on a time series analysis of daily positions using JPL's analyze_tseri software and are products of a NASA-funded (MEaSUREs) project at JPL and SIO. JPL and SIO use a common source of metadata (e.g., antenna height, antenna model) as available from the SOPAC database (sopac-old.ucsd.edu/sectorREADME.html).

\subsection{CANADIAN SPATIAL REFERENCE SYSTEM-PRECISE POINT POSITIONING (CSRS-PPP) ONLINE SERVICE}

The CSRS-PPP is an online post-processing service providing a PPP solution for GPS-only, GLONASS-only, and combined GPS/GLONASS observation data. The user sends the file of observation data whether single or dual frequency receivers to CSRS-PPP online postprocessing and receiving the precise position via email. After loading the observation data file the user choice to compute precise positions in either North American Datum of 1983 (NAD83) or International Terrestrial Reference Frame (ITRF).

When observation data obtained from dual frequency receiver is uploaded to the system. The CSRS-PPP online service using the ionosphere free linear combinations of measurements on L1 and L2 carriers in order to get rid of the first order ionospheric effects. If observation data obtained from single frequency receiver is used, CSRS-PPP employs only IGS Total Electron Content (TEC) maps produced at 2-hour interval in Ionosphere Map Exchange (IONEX) format to deal with the ionospheric effects. CSRS-PPP uses the pressure and temperature data 
obtained from Global Pressure and Temperature Model (GPT) in order to estimate the zenith hydrostatic and wet tropospheric delays.

It implements Davis et al. Model for zenith dry delay and the Hopfield Model for zenith wet delay. Furthermore, it utilizes the Global Mapping Function (GMF) to compute the total tropospheric delay in the line-of-sight direction.

The CSRS-PPP uses the best available ephemeris (i.e. ultra-rapid, rapid or final) when processing the observation data and uses the IGS ANTEX files for the satellite and receiver antenna phase center corrections (Deliktas, H.,2016).

\section{METHODOLOGY}

- Firstly, using the Trimble Business Center (TBC) technique for processing the IGS stations by fixing the BSHM station and determine the positioning of the other IGS stations (DRAG, RAMO, NICO and MERS). The coordinates of BSHM are computed from SOPAC by using the SECTOR tool. The Cartesian coordinates $(\mathrm{X}, \mathrm{Y}, \mathrm{Z})$ for all stations are obtained on ITRF 2008. The TBC technique used GPS observations only and the elevation mask angle of 15 degrees.

- In the TBC technique, the approximate length of baselines from BSHM to DRAG, RAMO, NICO and MERS are $136 \mathrm{~km}, 243 \mathrm{~km}, 302 \mathrm{~km}$ and $426 \mathrm{~km}$ respectively.

- Secondly, using the CSRS-PPP technique to estimate the coordinates of IGS stations on ITRF2014 and using GPS and GLONASS observations (https://webapp.geod.nrcan.gc.ca/geod/tools-outils/ppp.php).

- Finally, using the SECTOR tool technique at SOPAC to get the IGS stations coordinates on the ITRF2008 by using GPS observation (http://sopacold.ucsd.edu/sector.shtml).

- In all techniques subtracted the coordinates for the IGS stations which obtained from one day of observation in any month and the successive month to determine the Vector Length (VL) between every successive two months in 2018 and 2019 years.

- Using the Cartesian coordinates obtained from the SOPAC technique as reference to get the Position Error (PE) between these coordinates and other coordinates obtained from TBC and CSRS-PPP techniques for all IGS stations and all months.

$$
\text { Position Error }(\mathrm{PE})=\mathrm{SQRT}\left[\left(\mathrm{X}_{\mathrm{Ref}}-\mathrm{X}_{\mathrm{Com}}\right)^{2}+\left(\mathrm{Y}_{\mathrm{Ref}}-\mathrm{Y}_{\mathrm{Com}}\right)^{2}+\left(\mathrm{Z}_{\mathrm{Ref}}-\mathrm{Z}_{\mathrm{Com}}\right)^{2}\right]
$$

$\mathrm{X}_{\text {Ref, }} \mathrm{Y}_{\mathrm{Ref}, \mathrm{Z}_{\mathrm{Ref}}}:$ The reference coordinates.

$\mathrm{X}_{\mathrm{Com}}, \mathrm{X}_{\mathrm{Com}}, \mathrm{X}_{\mathrm{Com}}$ : The computed coordinates.

- To know the seasons meteorological which represents the months in the year to illustrate the highest Position Error (PE) through seasons see table (1).

Table 1: Seasons meteorological (Dates shown apply to the Northern Hemisphere) (https://www.calendarpedia.com/when-is/summer.html).

\begin{tabular}{|c|c|c|}
\hline Season & Start & End \\
\hline Spring & 1 March & 31 May \\
\hline Summer & 1 June & 31 August \\
\hline Autumn & 1 September & 30 November \\
\hline Winter & 1 December & 28 (29) February \\
\hline
\end{tabular}

\section{RESULTS}

When subtracted the coordinates for the IGS stations obtained from one day of observation in any month and the next month to determine the Vector Length (VL), it was found that the VL between the coordinates of points between every two consecutive months is not constant.

The results obtained by using TBC in 2018 illustrate that the difference between months is changing, but the highest values of the Vector Length (VL) between two consecutive months for all IGS stations at FEB- MAR, MAR-APR, JUN-JUL and JUL-AUG. In the second technique, CSRS-PPP gives the highest values of Vector Length (VL) are different in all IGS 
stations and the results of Vector Length (VL) obtained by the SOPAC technique are consistent see figures (2, 3, 4 and 5). In MERS station see figure (5) some days of observations data in AUG and SEP are not available. This was the reason why there were no coordinates for this point when treating with TBC and CSRS-PPP, but when using the SECTOR tool technique at SOPAC, the difference in the coordinates of this point between every two consecutive months was consistent except for JUL-AUG, and this is due to the data not available for August.

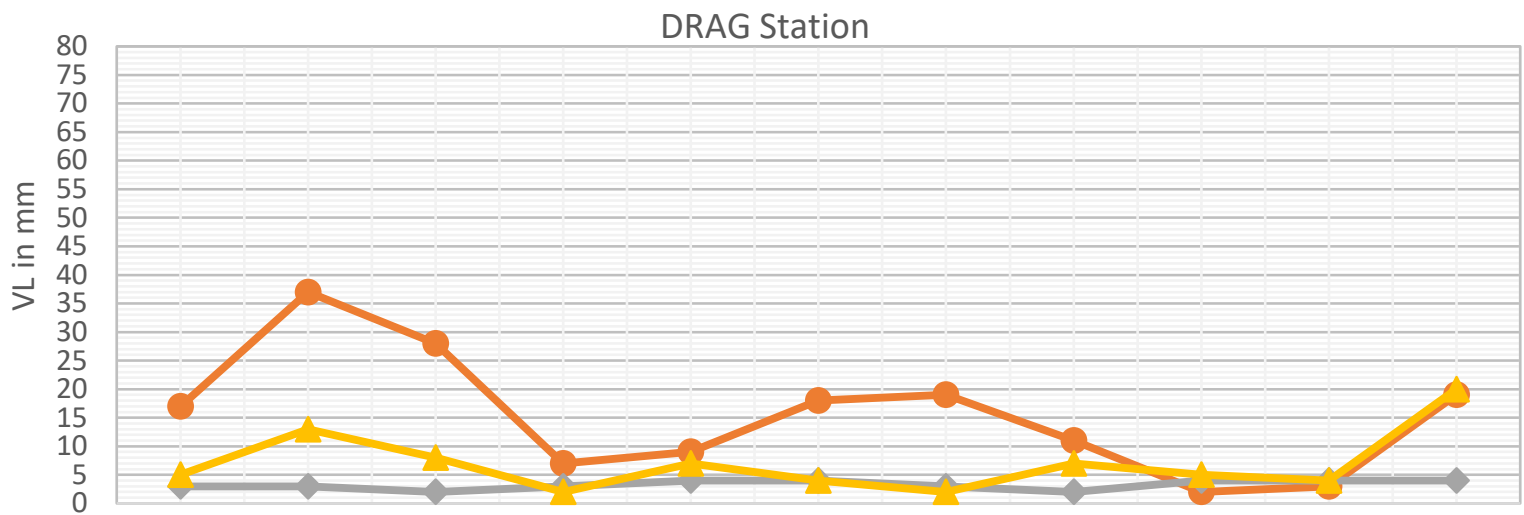

JAN- FEB FEB- MAR MAR-APR APR-MAY MAY-JUN JUN-JUL JUL-AUG AUG-SEP SEP-OCT OCT-NOV NOV-DEC -TBC $\longrightarrow$ SOPAC $\longrightarrow$ CSRS-PPP

Figure 2: The Vector Length (VL) for DRAG Station Between Every Two Successive Months by Using Three Techniques in 2018.

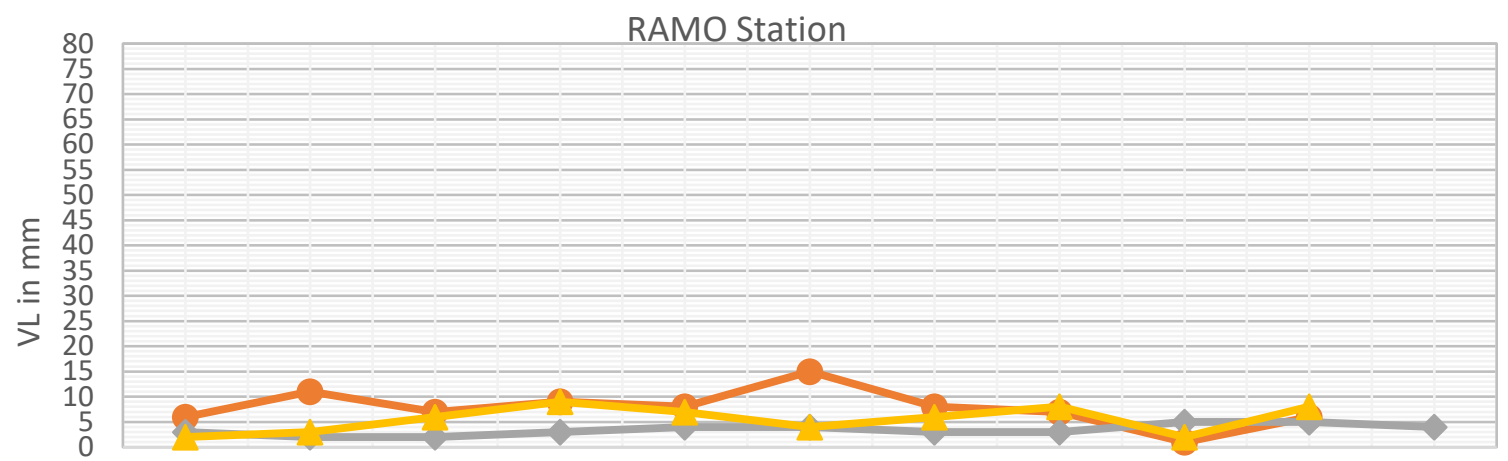

JAN- FEB FEB- MARMAR-APRAPR-MAY MAY-JUN JUN-JUL JUL-AUG AUG-SEP SEP-OCT OCT-NOV NOV-DEC - TBC $\longrightarrow$ SOPÁ $\longrightarrow$ CSRS-PPP

Figure 3: The Vector Length (VL) for RAMO Station Between Every Two Successive Months by Using Three Techniques in 2018.

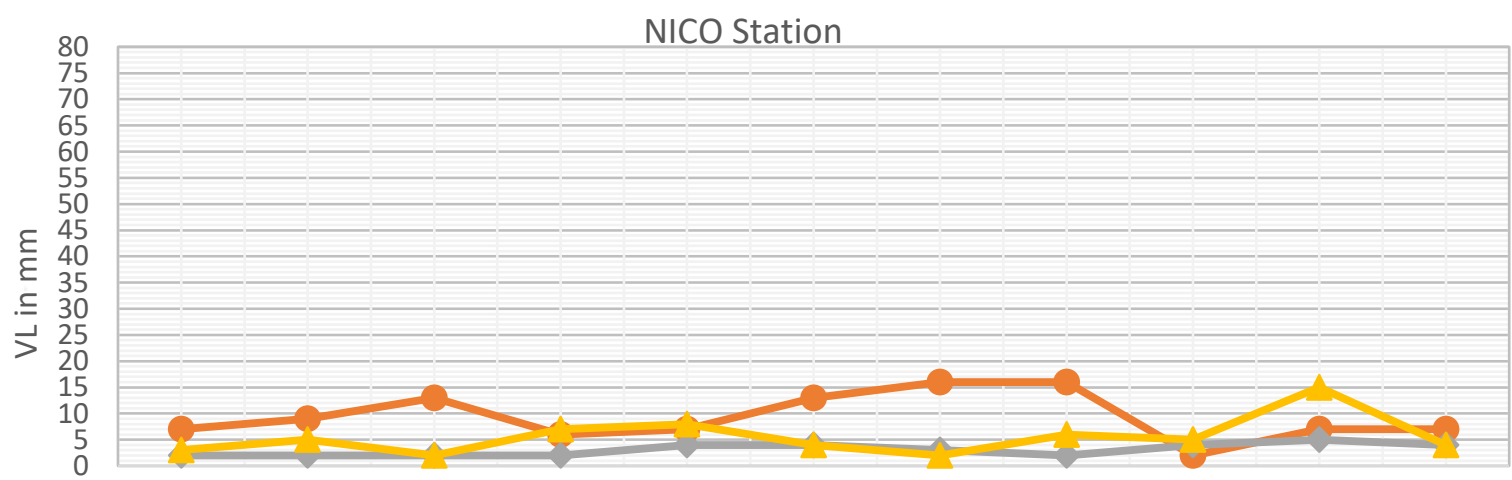

JAN- FEB FEB- MARMAR-APR APR-MAY MAY-JUN JUN-JUL JUL-AUG AUG-SEP SEP-OCT OCT-NOV NOV-DEC $\longrightarrow$ TBC $\leadsto$ SOPAC $\longrightarrow$ CSRS-PPP

Figure 4: The Vector Length (VL) for NICO Station Between Every Two Successive Months by Using Three Techniques in 2018. 


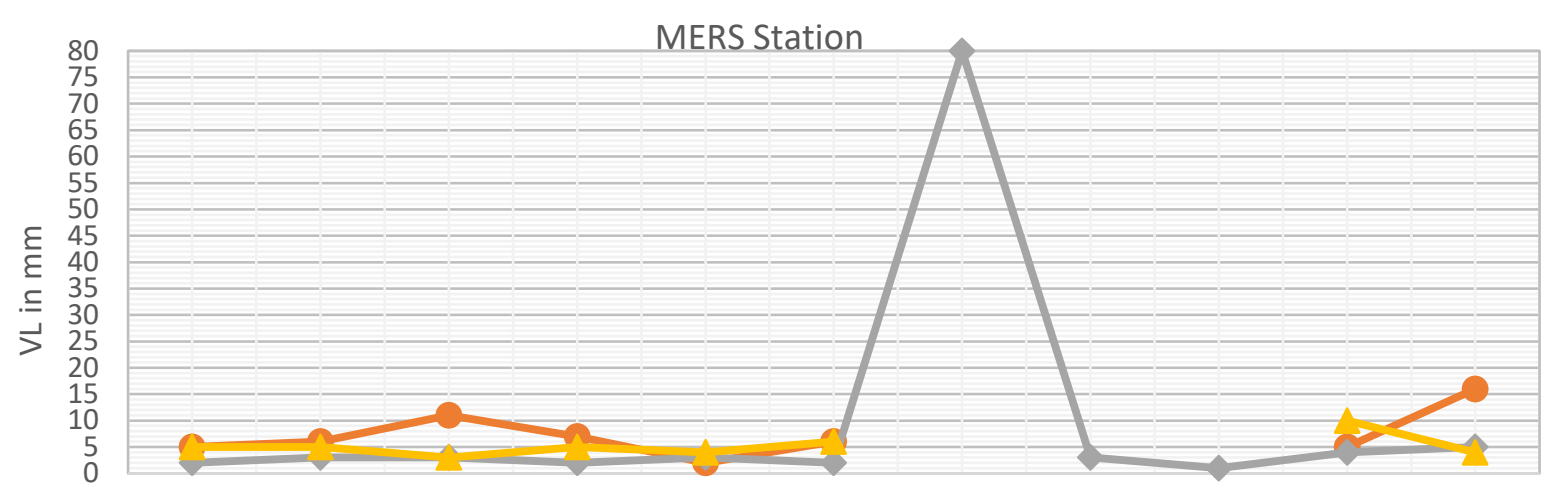

JAN- FEB FEB- MAR MAR-APR APR-MAY MAY-JUN JUN-JUL JUL-AUG AUG-SEP SEP-OCT OCT-NOV NOV-DEC MOnths - SOPAC - CSRS-PPP

Figure 5: The Vector Length (VL) for MERS Station Between Every Two Successive Months by Using Three Techniques in 2018.

In 2019 when using the TBC the Vector Length (VL) between months are hight, but the peak of Vector Length (VL) is between July-August and August-September in four IGS stations. Also, when using CSRS-PPP, the changes were significant between successive months the peak of Vector Length (VL) for each IGS station is different from the others. Finally, when computing the Vector Length (VL) obtained by SOPAC for all IGS stations are nearly homogeneous see figures $(6,7,8$ and 9$)$.

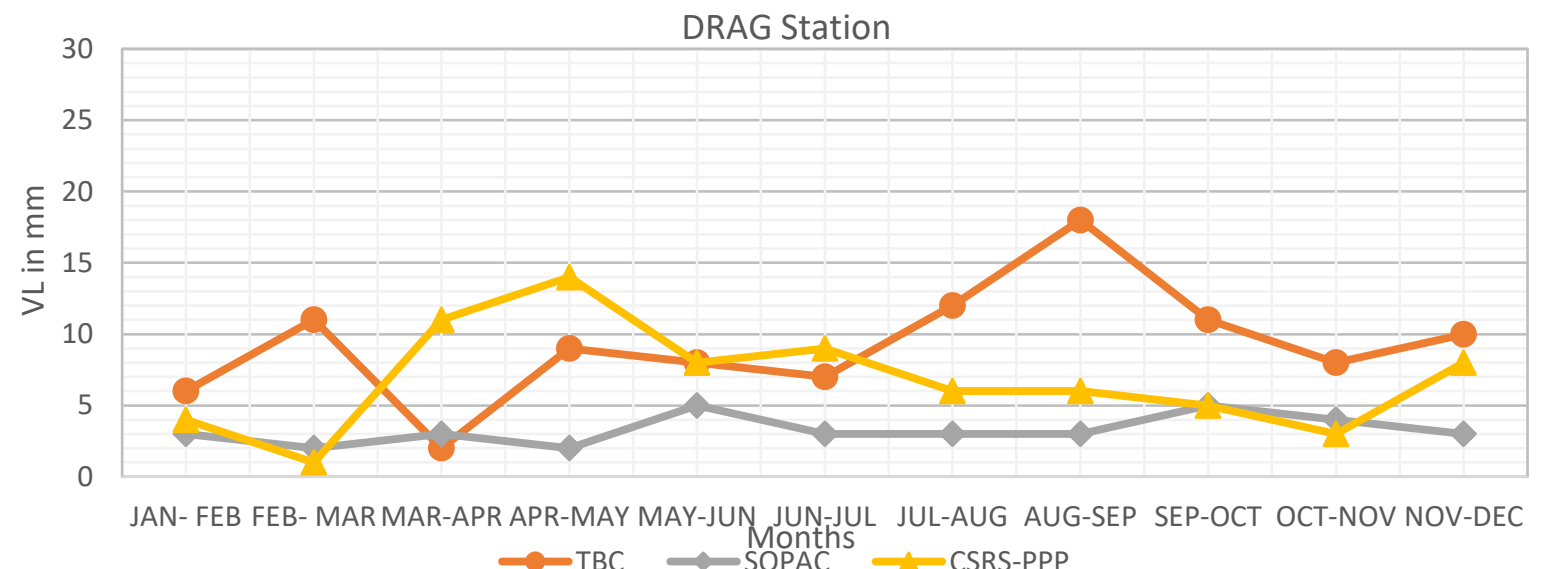

Figure 6: The Vector Length (VL) for DRAG Station Between Every Two Successive Months by Using Three Techniques in 2019.

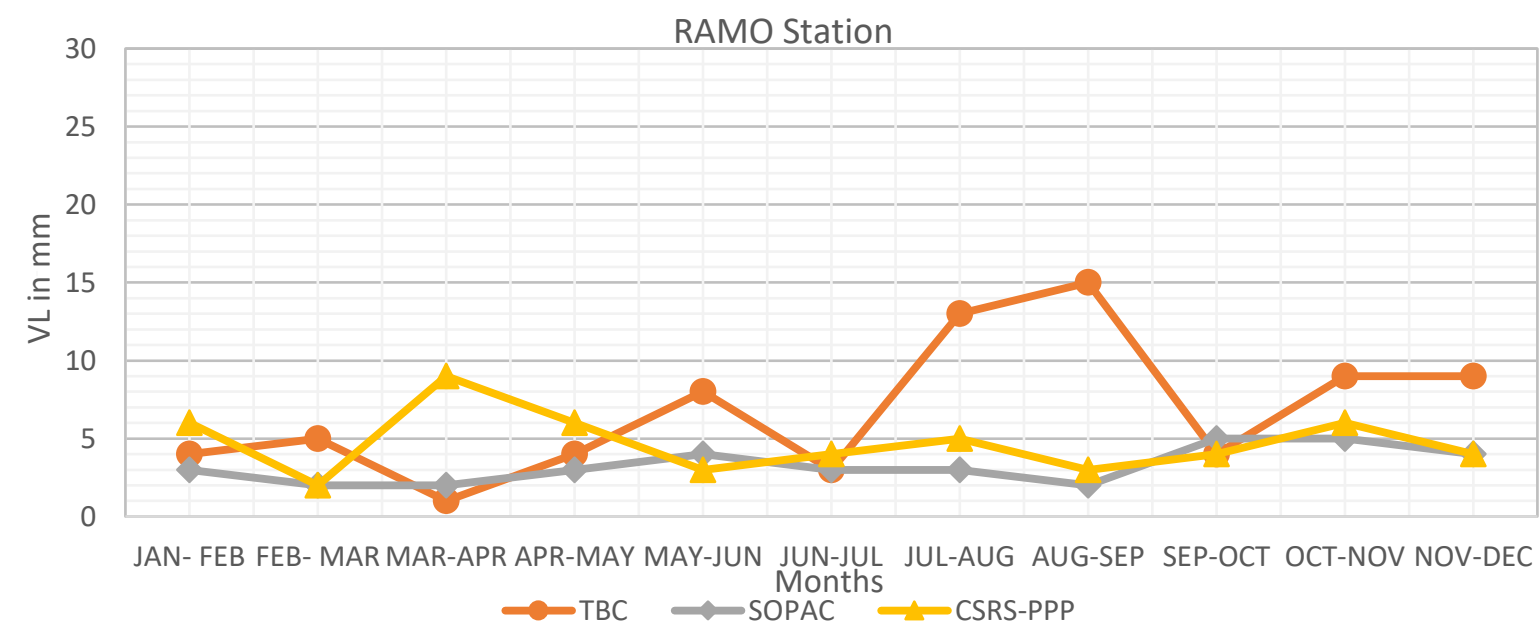

Figure 7: The Vector Length (VL) for RAMO Station Between Every Two Successive Months by Using Three Techniques in 2019. 


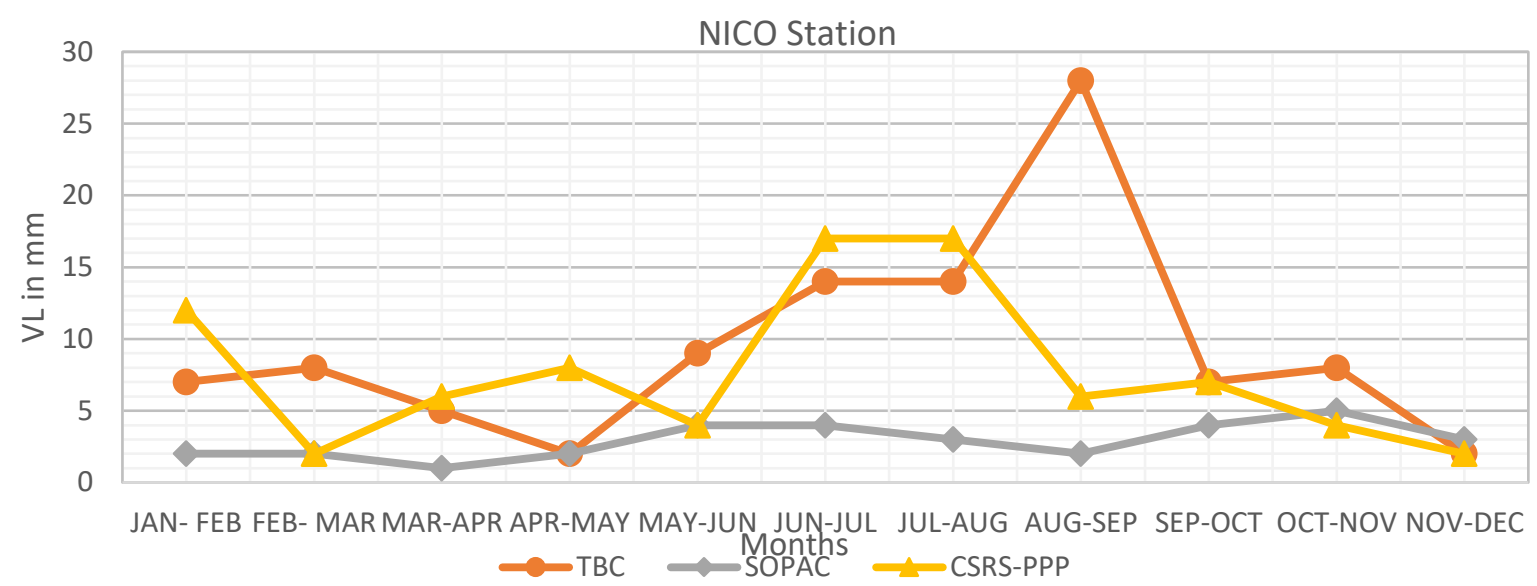

Figure 8: The Vector Length (VL) for NICO Station Between Every Two Successive Months by Using Three Techniques in 2019.

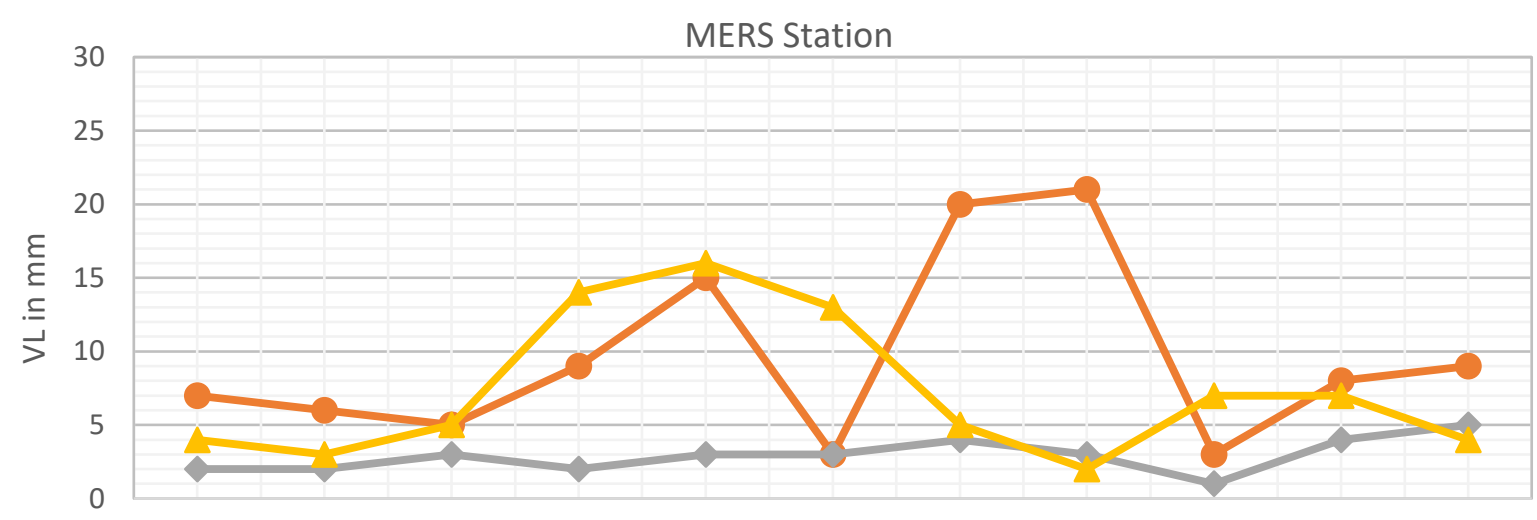

JAN- FEB FEB- MARMAR-APR APR-MAY MAY-JUN JUN-JUL JUL-AUG AUG-SEP SEP-OCT OCT-NOV NOV-DEC

Months
SOPAC

Figure 9: The Vector Length (VL) for MERS Station Between Every Two Successive Months by Using Three Techniques in 2019.

From the result of SOPAC, coordinates were consistent for all months of the years 2018 and 2019. This is evident from figures (2 to 9) so, in this research, we take the coordinates that we obtained from SOPAC as fixed coordinates of the IGS stations, and we calculated the Position Error (PE) between both the coordinates that we obtained from TBC and the fixed coordinates of the points on the day of observation for each month. Also, the Position Error (PE) between the coordinates obtained from CSRS-PPP and the fixed coordinates of the stations obtained by SOPAC were computed.

In 2018 the Position Error (PE) for TBC and SOPAC are shown in the figures (10, 11, 12 and 13). The highest values of Position Error (PE) at the IGS stations appear in the following months JAN, MAR, APR, JUL, AUG, OCT, NOV and DEC. The common months between the IGS stations which gives the maximum values of Position Error (PE) are JAN, MAR and JUL see figures (10, 11, 12 and 13). The maximum Position Error (PE) obtained from CSRSPPP and SOPAC it was in the following months JAN, FEB, MAR, APR, MAY, JUN, JUL, AUG, SEP, OCT and DEC. The JAN is the common month between the IGS stations which gives a high value of Position Error (PE) see figures (10, 11, 12 and 13). 


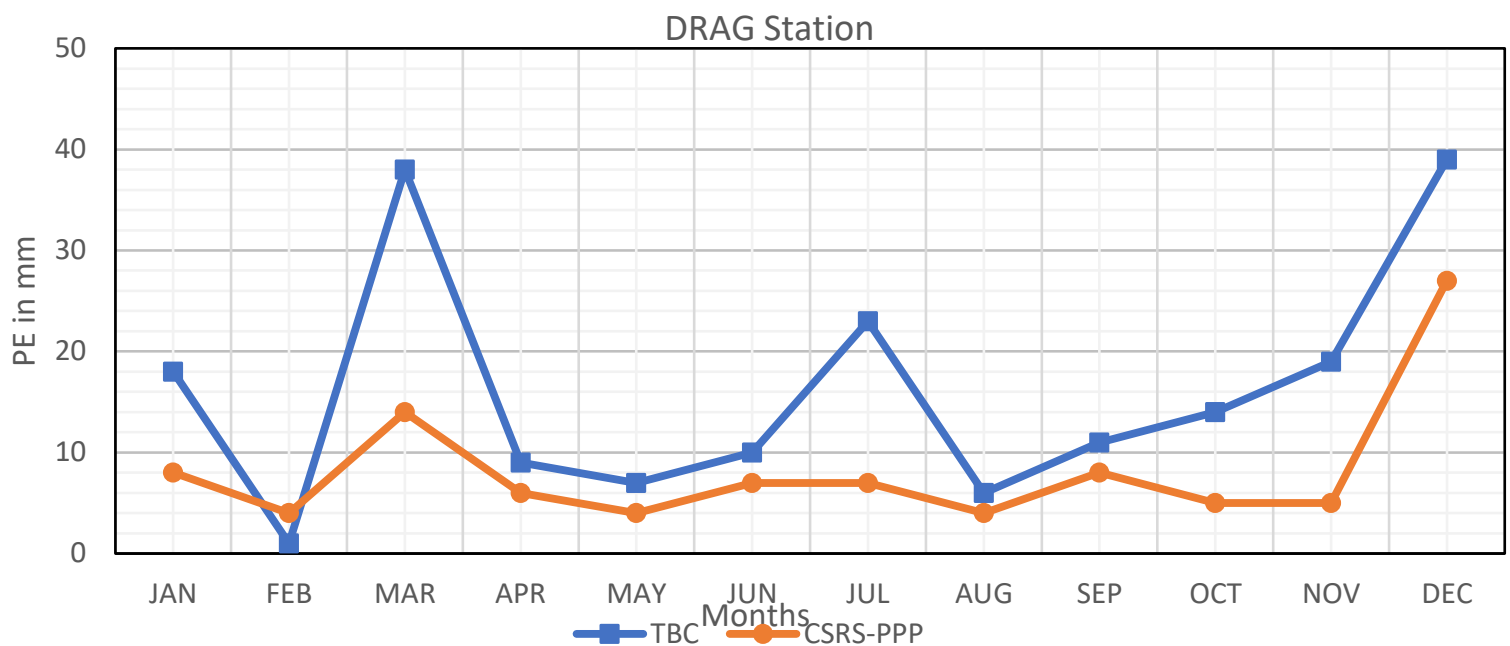

Figure 10: The Position Error (PE) for DRAG Station Obtained by SOPAC and Other Techniques Monthly in 2018.

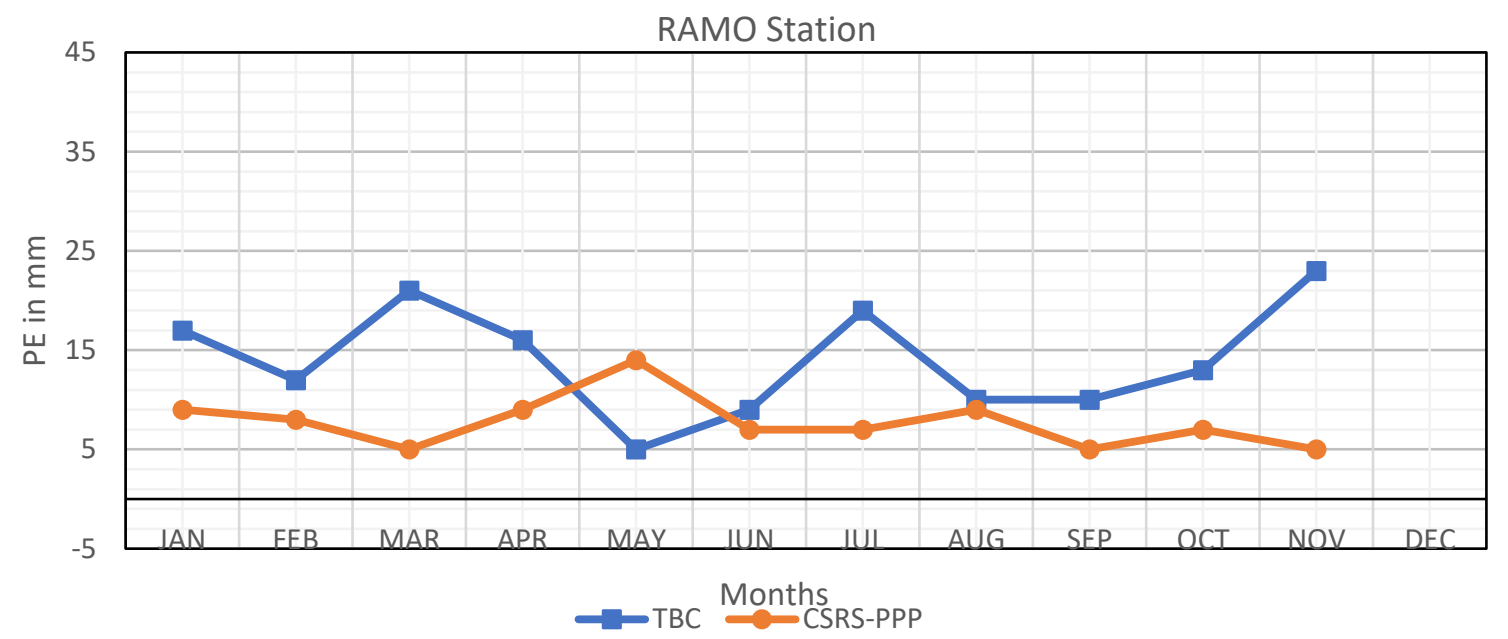

Figure 11: The Position Error (PE) for RAMO Station Obtained by SOPAC and Other Techniques Monthly in 2018.

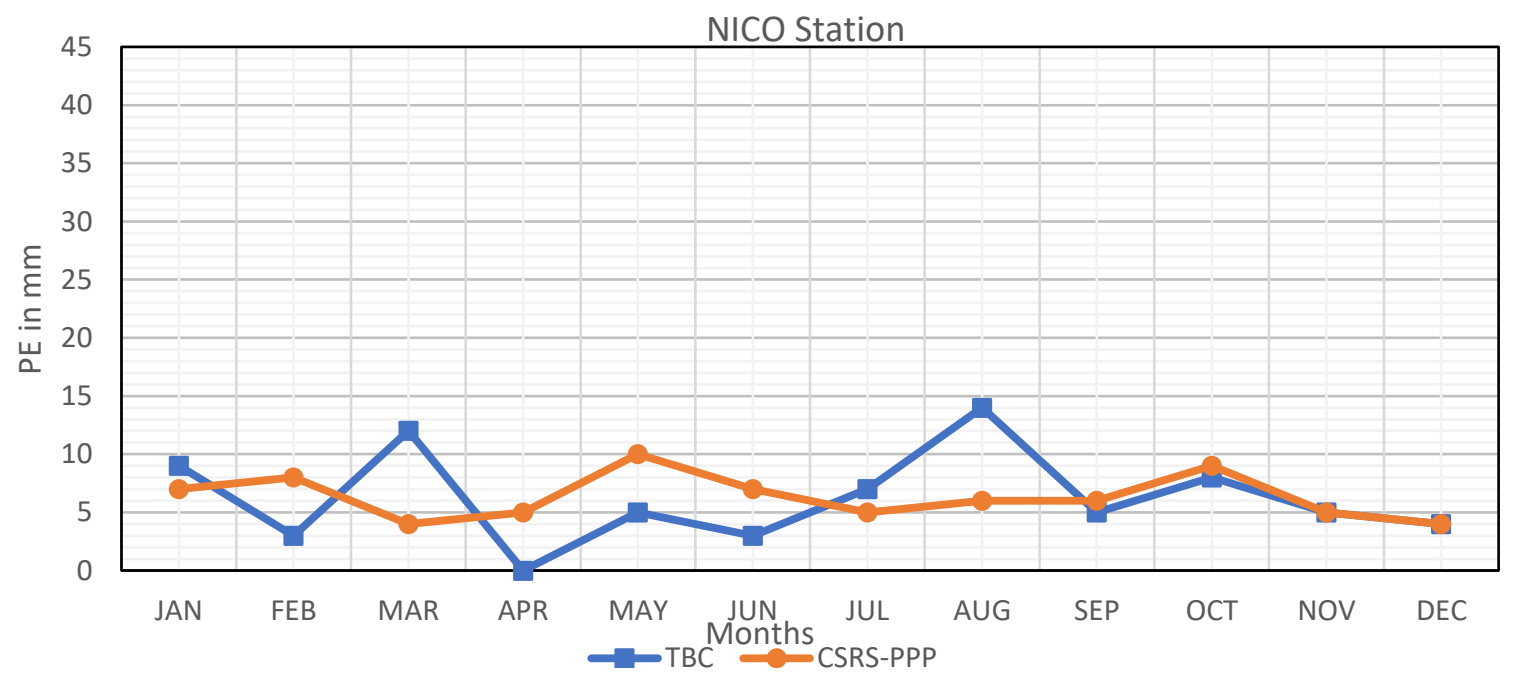

Figure 12: The Position Error (PE) for NICO Station Obtained by SOPAC and Other Techniques Monthly in 2018. 


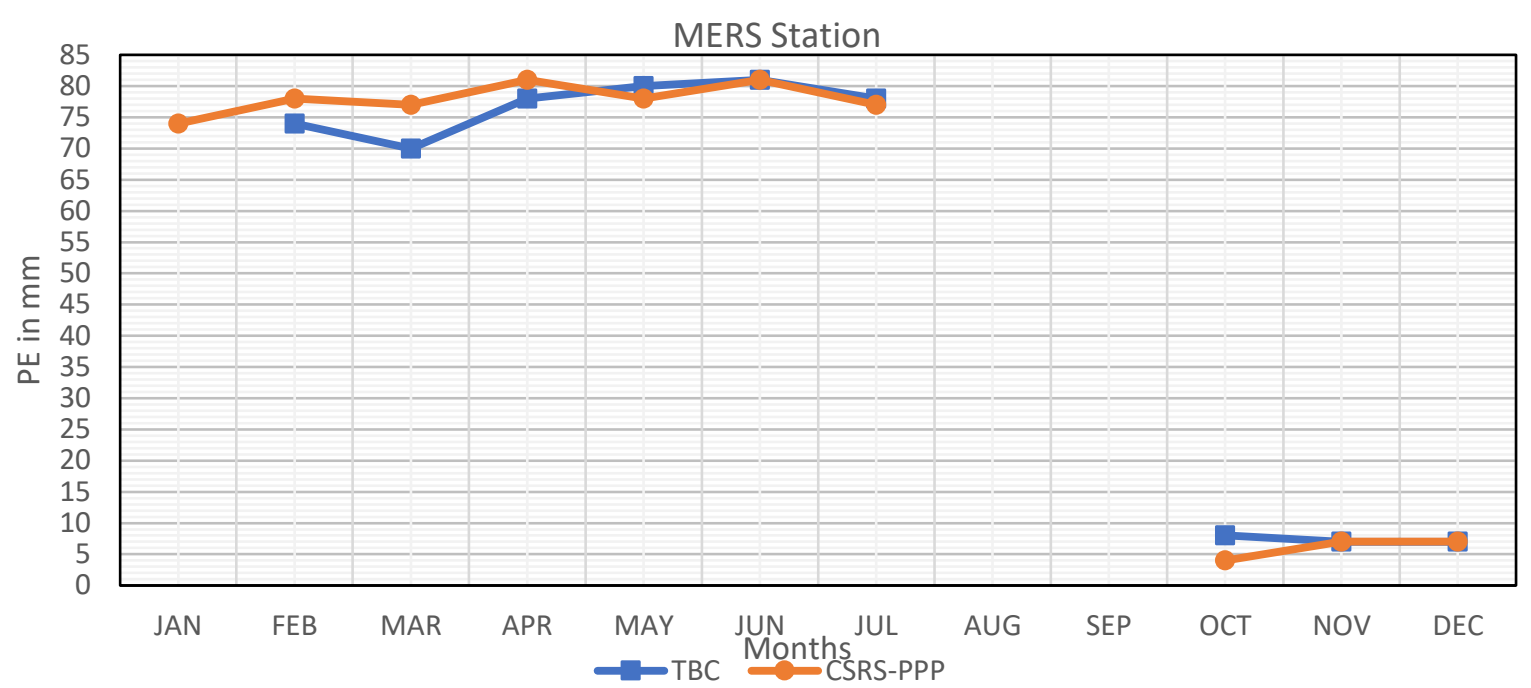

Figure 13: The Position Error (PE) for MERS Station Obtained by SOPAC and Other Techniques Monthly in 2018.

In 2019 the Position Error (PE) for TBC and SOPAC are shown in the figures (14, 15, 16 and 17). The IGS stations give the highest values of Position Error (PE) in the following months MAR, MAY, JUN, JUL, AUG, OCT, NOV and DEC. The common months between the IGS stations which gives high values of Position Error (PE) are MAR, AUG and NOV see figures (14, 15, 16 and 17). The maximum Position Error (PE) obtained from CSRS-PPP and SOPAC it was in the following months FEB, MAR, APR, MAY, JUN, JUL, AUG, SEP, OCT, NOV and DEC. The common months between the IGS stations which gives higher values of Position Error (PE) are MAY and JUL, see figures (14, 15, 16 and 17).

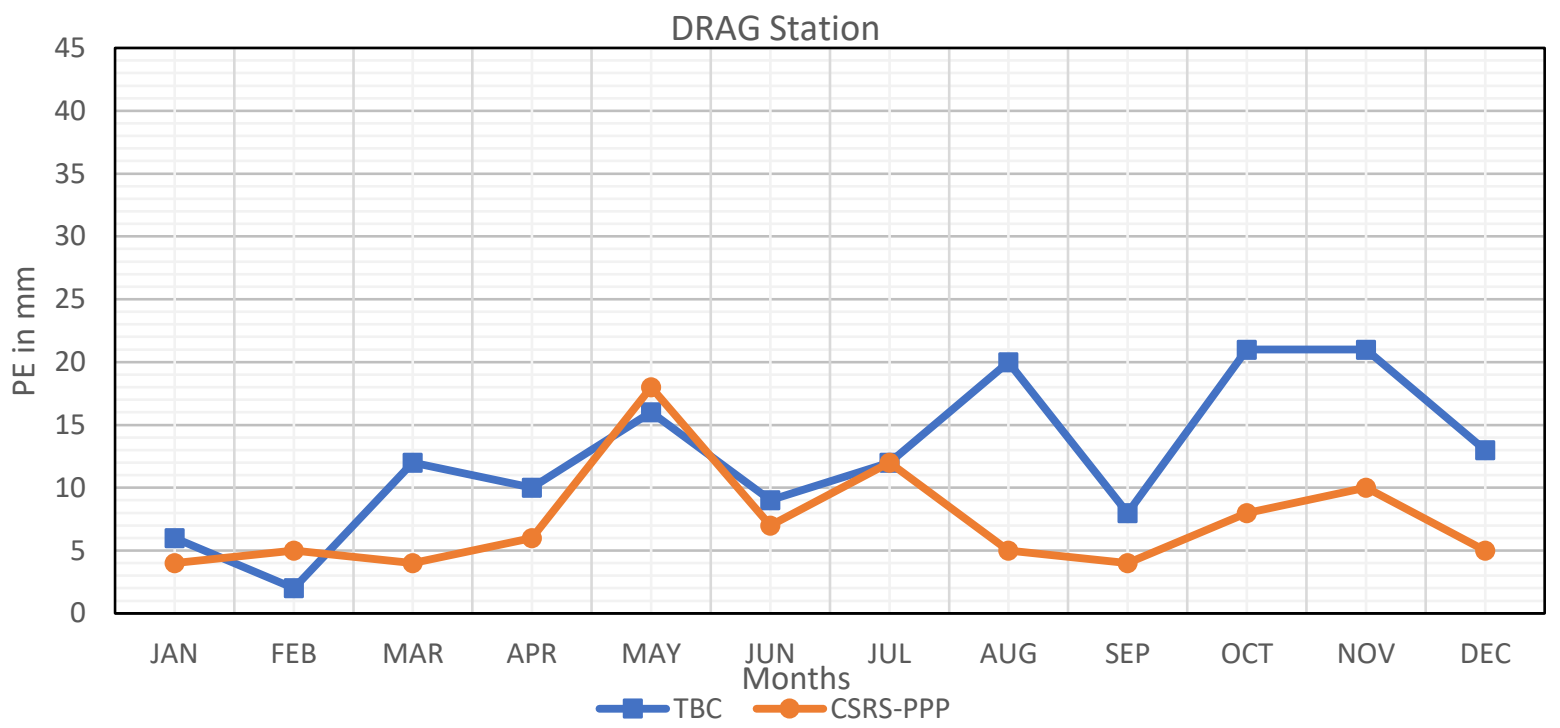

Figure 14: The Position Error (PE) for DRAG Station Obtained by SOPAC and Other Techniques Monthly in 2019. 


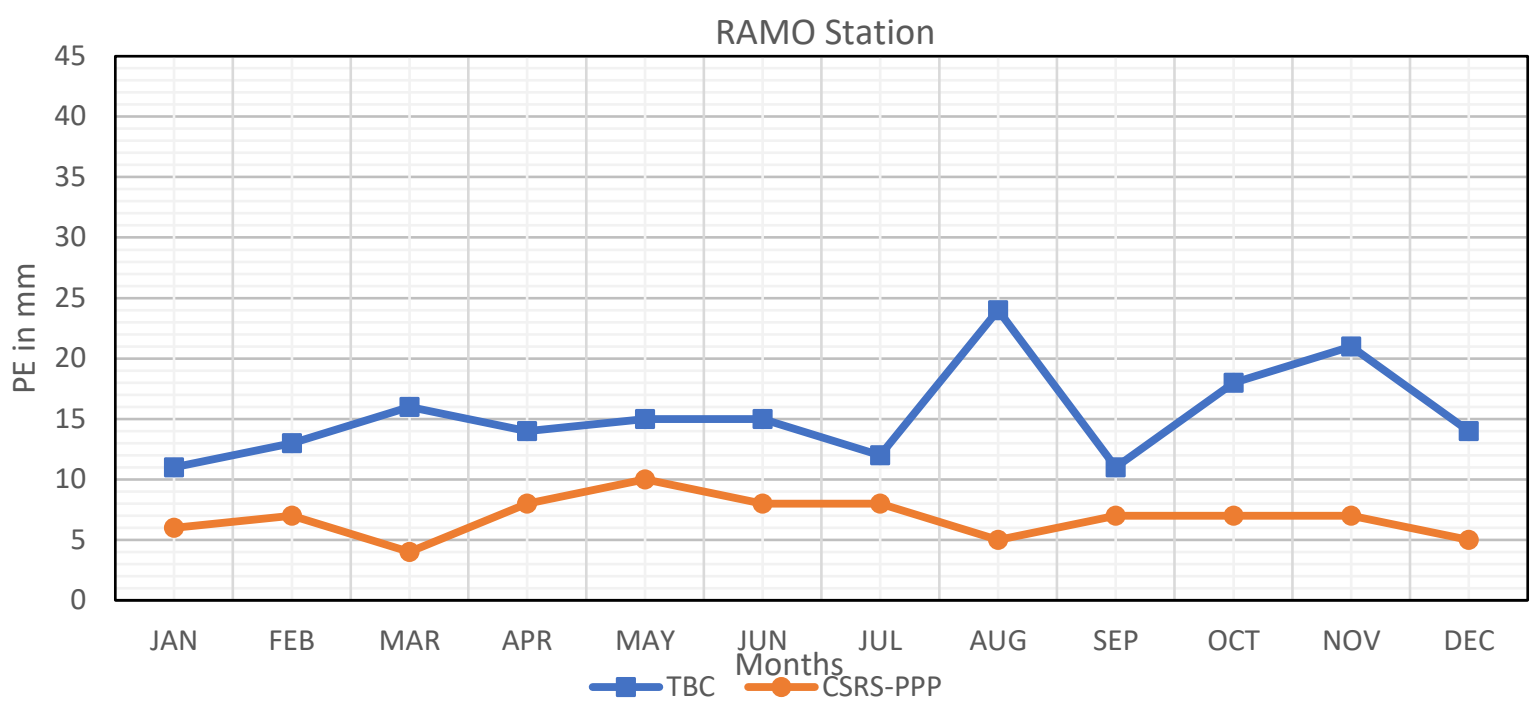

Figure 15: The Position Error (PE) for RAMO Station Obtained by SOPAC and Other Techniques Monthly in 2019.

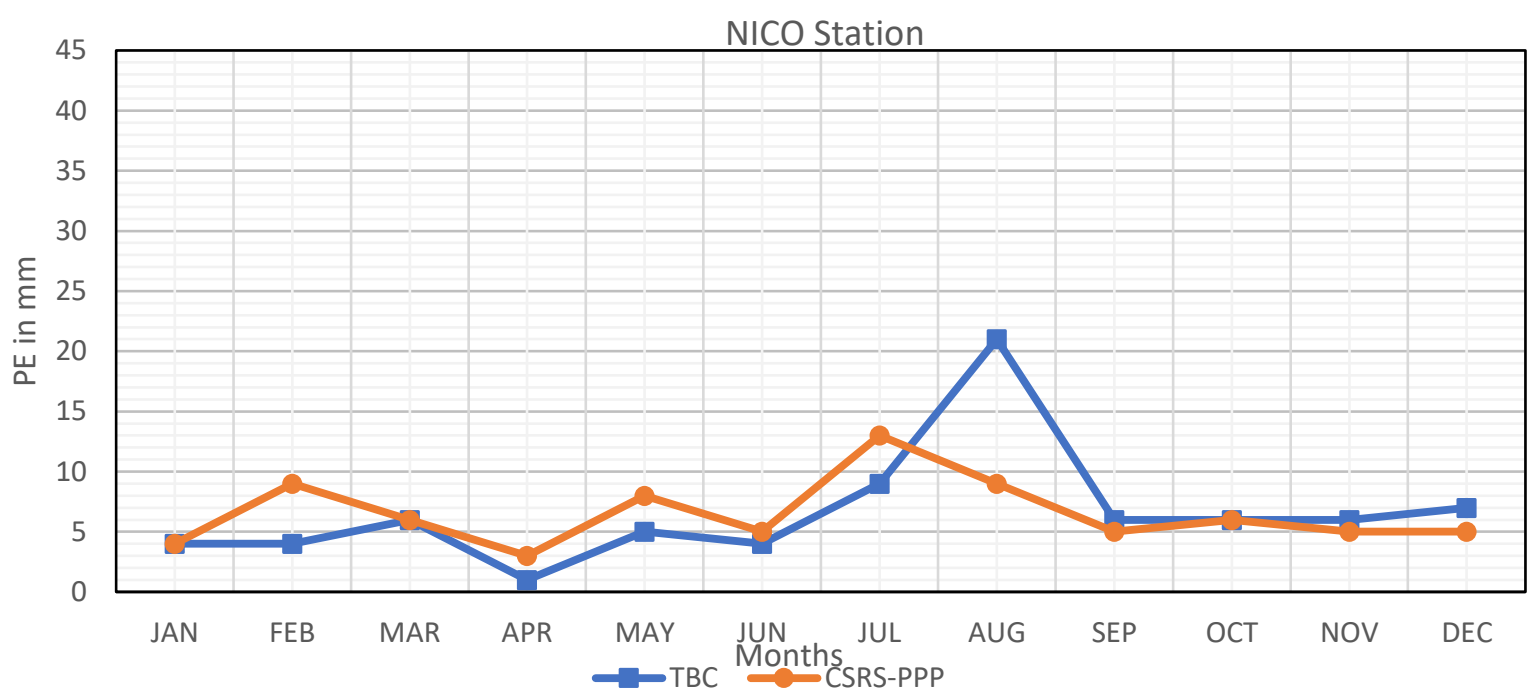

Figure 16: The Position Error (PE) for NICO Station Obtained by SOPAC and Other Techniques Monthly in 2019.

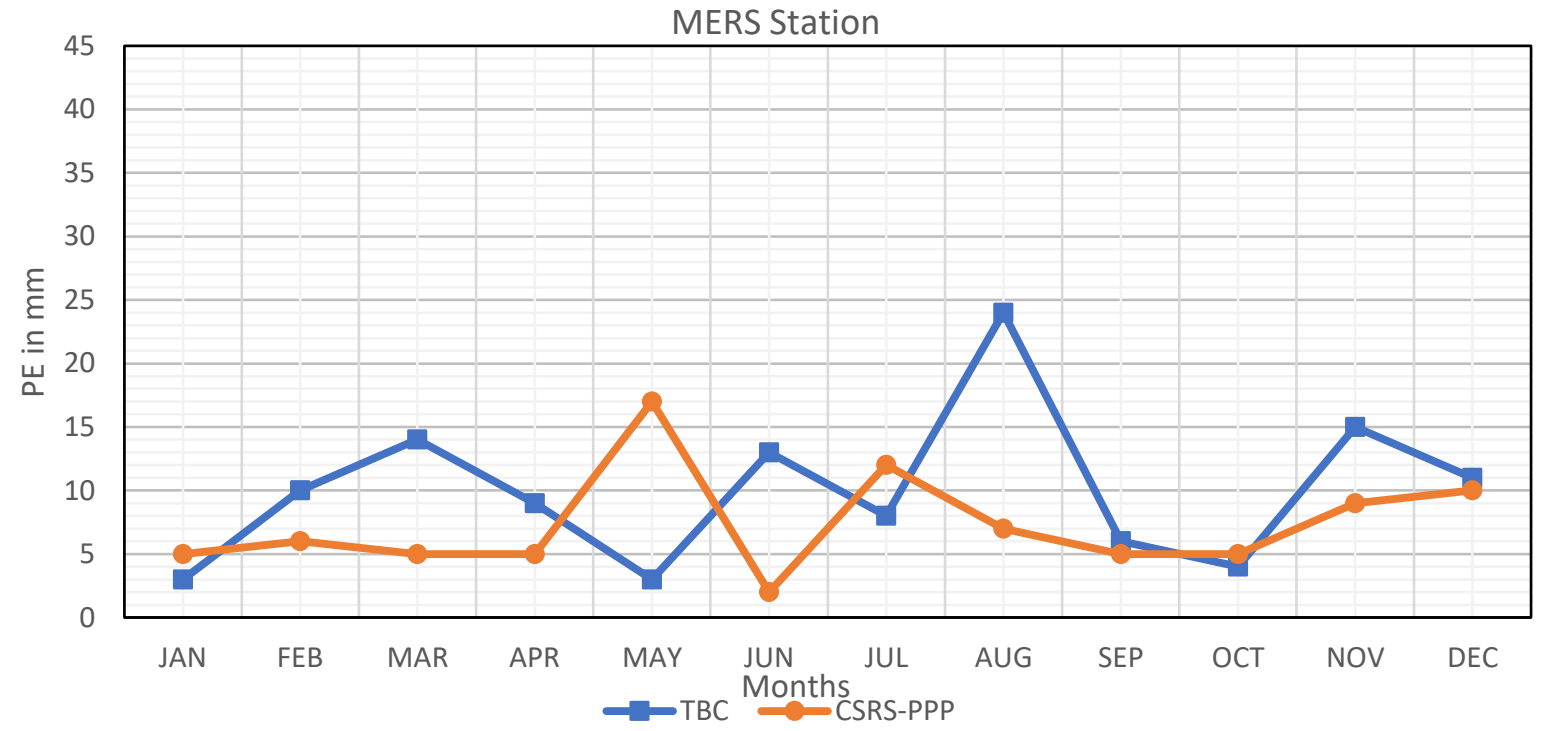

Figure 17: The Position Error (PE) for MERS Station Obtained by SOPAC and Other Techniques Monthly in 2019. 
When using the TBC technique, it is noticeable that the changes in the values of the maximum PDOP in most baseline lengths see tables (2 and 3 ) has no effect on Position Error (PE) see figures from 10 to 17.

Table 2: The processing duration and Maximum PDOP for deferent baselines processing in 2018

\begin{tabular}{|c|c|c|c|c|c|c|c|c|}
\hline Baseline & \multicolumn{2}{|c|}{ BSHM-DRAG } & \multicolumn{2}{c|}{ BSHM- RAMO } & \multicolumn{2}{c|}{ BSHM-NICO } & \multicolumn{2}{c|}{ BSHM-MERS } \\
\hline Month & $\begin{array}{c}\text { Processing } \\
\text { duration }\end{array}$ & $\begin{array}{c}\text { Maximum } \\
\text { PDOP }\end{array}$ & $\begin{array}{c}\text { Processing } \\
\text { duration }\end{array}$ & $\begin{array}{c}\text { Maximum } \\
\text { PDOP }\end{array}$ & $\begin{array}{c}\text { Processing } \\
\text { duration }\end{array}$ & $\begin{array}{c}\text { Maximum } \\
\text { PDOP }\end{array}$ & $\begin{array}{c}\text { Processing } \\
\text { duration }\end{array}$ & $\begin{array}{c}\text { Maximum } \\
\text { PDOP }\end{array}$ \\
\hline 04 JAN & $23: 59: 30$ & 5.755 & $23: 59: 30$ & 5.755 & $23: 59: 30$ & 5.755 & $23: 59: 30$ & 6.477 \\
\hline 05 FEB & $15: 30: 30$ & 6.492 & $23: 59: 30$ & 6.492 & $23: 59: 30$ & 7.517 & $23: 59: 30$ & 7.718 \\
\hline 08 MAR & $13: 08: 30$ & 6.825 & $23: 59: 30$ & 6.825 & $23: 59: 30$ & 8.366 & $23: 59: 30$ & 7.793 \\
\hline 06 APR & $22: 55: 00$ & 9.918 & $23: 59: 30$ & 11.236 & $23: 59: 30$ & 9.918 & $23: 59: 30$ & 15.455 \\
\hline 02 MAY & $23: 59: 30$ & 11.685 & $23: 59: 30$ & 12.471 & $23: 59: 30$ & 11.141 & $23: 59: 30$ & 11.141 \\
\hline 06 JUN & $23: 59: 30$ & 14.341 & $23: 59: 30$ & 15.350 & $23: 59: 30$ & 13.452 & $23: 44: 30$ & 15.644 \\
\hline 06 JUL & $23: 59: 30$ & 18.429 & $23: 59: 30$ & 19.938 & $23: 59: 30$ & 17.110 & $23: 59: 30$ & 17.110 \\
\hline 06 AUG & $17: 27: 00$ & 19.852 & $17: 27: 00$ & 19.852 & $23: 59: 30$ & 19.910 & & \\
\hline 03 SEP & $23: 59: 30$ & 13.198 & $23: 59: 30$ & 13.198 & $23: 59: 30$ & 19.951 & & \\
\hline 06 OCT & $23: 59: 30$ & 19.709 & $23: 59: 30$ & 19.768 & $23: 59: 30$ & 19.698 & $23: 59: 30$ & 19.698 \\
\hline 06 NOV & $14: 50: 00$ & 14.324 & $14: 50: 00$ & 14.324 & $23: 59: 30$ & 14.908 & $23: 59: 30$ & 16.367 \\
\hline 07 DEC & $23: 59: 30$ & 14.774 & & & $23: 59: 30$ & 14.774 & $23: 59: 30$ & 14.774 \\
\hline
\end{tabular}

Table 3: The processing duration and Maximum PDOP for deferent baselines processing in 2019

\begin{tabular}{|c|c|c|c|c|c|c|c|c|}
\hline Baseline & \multicolumn{2}{|c|}{ BSHM-DRAG } & \multicolumn{2}{c|}{ BSHM- RAMO } & \multicolumn{2}{c|}{ BSHM-NICO } & \multicolumn{2}{c|}{ BSHM-MERS } \\
\hline Month & $\begin{array}{c}\text { Processing } \\
\text { duration }\end{array}$ & $\begin{array}{c}\text { Maximum } \\
\text { PDOP }\end{array}$ & $\begin{array}{c}\text { Processing } \\
\text { duration }\end{array}$ & $\begin{array}{c}\text { Maximum } \\
\text { PDOP }\end{array}$ & $\begin{array}{c}\text { Processing } \\
\text { duration }\end{array}$ & $\begin{array}{c}\text { Maximum } \\
\text { PDOP }\end{array}$ & $\begin{array}{c}\text { Processing } \\
\text { duration }\end{array}$ & $\begin{array}{c}\text { Maximum } \\
\text { PDOP }\end{array}$ \\
\hline 04 JAN & $23: 59: 30$ & 9.828 & $23: 59: 30$ & 9.828 & $23: 59: 30$ & 9.828 & $23: 59: 30$ & 9.828 \\
\hline 05 FEB & $23: 59: 30$ & 6.244 & $23: 59: 30$ & 6.244 & $23: 59: 30$ & 8.334 & $23: 59: 30$ & 6.244 \\
\hline 08 MAR & $23: 59: 30$ & 17.189 & $23: 59: 30$ & 18.428 & $23: 59: 30$ & 16.416 & $23: 59: 30$ & 16.416 \\
\hline 06 APR & $23: 59: 30$ & 6.124 & $23: 59: 30$ & 6.124 & $23: 59: 30$ & 6.124 & $23: 59: 30$ & 6.768 \\
\hline 02 MAY & $23: 59: 30$ & 5.957 & $23: 59: 30$ & 5.957 & $23: 59: 30$ & 8.238 & $23: 59: 30$ & 12.084 \\
\hline 06 JUN & $23: 59: 30$ & 12.777 & $23: 59: 30$ & 12.777 & $23: 59: 30$ & 14.187 & $23: 59: 30$ & 18.623 \\
\hline 06 JUL & $23: 59: 30$ & 12.321 & $23: 59: 30$ & 13.205 & $23: 59: 30$ & 11.78 & $23: 59: 30$ & 11.78 \\
\hline 06 AUG & $23: 59: 30$ & 14.676 & $23: 59: 30$ & 15.689 & $23: 59: 30$ & 14.045 & $23: 59: 30$ & 14.045 \\
\hline 03 SEP & $23: 59: 30$ & 17.189 & $23: 59: 30$ & 18.428 & $23: 59: 30$ & 16.416 & $23: 59: 30$ & 16.416 \\
\hline 06 OCT & $23: 59: 30$ & 16.757 & $23: 59: 30$ & 17.001 & $23: 59: 30$ & 14.918 & $23: 59: 30$ & 14.918 \\
\hline 06 NOV & $23: 59: 30$ & 14.37 & $23: 59: 30$ & 15.701 & $23: 59: 30$ & 14.052 & $23: 59: 30$ & 17 \\
\hline 07 DEC & $23: 59: 30$ & 13.652 & $23: 59: 30$ & 13.652 & $23: 59: 30$ & 13.896 & $23: 59: 30$ & 13.445 \\
\hline
\end{tabular}

\section{CONCLUSIONS}

- Finally, it is clear that the change in coordinates of stations is not constant from month to month in the same year. Also, the change in coordinates of stations from one year to another for the same month is not fixed.

- When using TBC the higher Position Error (PE) in Spring and Winter the maximum values are $38 \mathrm{~mm}$ and $39 \mathrm{~mm}$ respectively and the maximum values of PE in Summer and Autumn are $24 \mathrm{~mm}$ and $23 \mathrm{~mm}$ respectively. Also, when using the CSRS-PPP the higher PE in Spring and Winter the maximum values are $18 \mathrm{~mm}$ and $27 \mathrm{~mm}$ respectively and the maximum values in Summer and Autumn are $13 \mathrm{~mm}$ and $11 \mathrm{~mm}$ respectively.

- Using TBC the common summer months in the two years, which give higher PE are July and August.

- October and November are common autumn months that give the higher PE in the two years by using TBC.

- March and December are the most common months in spring and winter respectively, that given the higher PE by using TBC in the two years.

- Using TBC, the Vector Length (VL) between every two successive months is increased at the beginning of a new season and the end of another season, this is illustrated by AUG-SEP, FEB-MAR, NOV-DEC and MAY-JUN. 
- In CSRS-PPP, the Vector Length (VL) between every two successive months, increases at MAR-APR, APR-MAY, MAY-JUN, JUN-JUL, JUL-AUG and AUGSEP.

\section{REFERENCES}

1. Akhoondzadeh, M., Sharifi,M., Farzaneh,S and Sabzehee,F (2018). TEC Regional Modeling and Prediction Using ANN Method and Single Frequency Receivers over IRAN. ANNALS OF GEOPHYSICS, 61, 1, GM103, 2018; doi: 10.4401/ag-7297.

2. Celestino, C., Kuga, H., Yamaguti, W and da Silva, A (2012). Assessment of the Ionospheric and Tropospheric Effects in Location Errors of Data Collection Platforms in Equatorial Region during High and Low Solar Activity Periods. Hindawi Publishing Corporation, Mathematical Problems in Engineering, Volume 2012, Article ID 734280, 15 pages.

3. Cole, D., Wang, J., Ouyang, G and Wang, J (2009). Analysis on Temporal-Spatial Variations of Australian TEC. Observing our Changing Earth, International Association of Geodesy Symposia Volume 133, Springer-Verlag Berlin Heidelberg 2009.

4. Deliktas, H (2016). Investigation on the contribution of GLONASS observations to GPS Precise Point Positioning (PPP). Thesis, Master of Science, Ohio State University,2016.

5. ftp://cddis.nasa.gov/gnss/products/

6. http://sopac-old.ucsd.edu/dataBrowser.shtml.

7. http://sopac-old.ucsd.edu/sector.shtml.

8. http://sopac-old.ucsd.edu/sectorREADME.html

9. http://www.igs.org/network.

10. https://webapp.geod.nrcan.gc.ca/geod/tools-outils/ppp.php

11. https://www.calendarpedia.com/when-is/summer.html

12. Unavco(2021). www.unavco.org/software/data-processing/postprocessing/tbc/tbc.html

13. Webster,I (1993). A Regional Model for the Prediction of Ionospheric Delay for Single Frequency Users of the Global Positioning System. Department of Geodesy and Geomatics Engineering, University of New Brunswick, Apri11993. 